\title{
CARACTERÍSTICAS PRODUTIVAS, FÍSICAS E QUÍMICAS DE FRUTOS DE CULTIVARES DE PESSEGUEIROS SOBRE DOIS PORTA-ENXERTOS NO OESTE DO ESTADO DE SÃO PAULO ${ }^{1}$
}

\author{
SÔNIAMARIA NALESSO MARANGONI MONTES² ${ }^{2}$ APARECIDACONCEIÇÃO BOLIANI ${ }^{3}$, ADALTON RAGA $^{4}$, \\ PEDRO CÉSAR DOS SANTOS ${ }^{3}$, LUIZ DE SOUZA CORREA $^{3}$, JOSIANE TAKASSAKI FERRARI $^{4}$
}

RESUMO - Objetivou-se avaliar as características físicas e químicas de seis cultivares de pessegueiros sobre os porta-enxertos Okinawa e Umê. O trabalho foi desenvolvido no Pólo Regional Alta Sorocabana-APTA, Presidente Prudente-SP, em 2004/2006. Foram avaliados a massa, comprimento, diâmetros sutural dos frutos, produção por planta, teor de sólidos solúveis (SS) e acidez titulável (AT). As avaliações permitiram concluir que os porta-enxertos influenciaram na massa dos frutos, tendo sobressaído o Umê, com frutos de maior massa média. Em 2006, ocorreu aumento significativo na produtividade de todas as cultivares, sobressaindo-se as cvs. Talismã e Doçura 2, com valores acima da média. A cv. Doçura 2 sobre 'Okinawa' destacou-se por reunir melhores características físicas dos frutos e produção por planta. As cvs. Talismã e Dourado 2 produziram frutos com maiores valores de massa, comprimento e diâmetro sutural, sobre os porta-enxertos 'Okinawa' e Umê. A cv. Tropical destacou-se pelos atributos de qualidade, independentemente do porta-enxerto.

Termos para indexação: Prunus persica L., qualidade,produção, ratio.

\section{PRODUTIVE AND PHYSICAL-CHEMICAL CHARACTERISTICS OF PEACH CULTIVAR FRUITS ON TWO ROOTSTOCKS ON THE WESTERN OF SÃO PAULO STATE}

ABSTRACT- The objective of the study was to evaluate the physical-chemical characteristics of six peach cultivars over the Okinawa and Umê rootstocks. The experiment was carried out at Polo Regional Alta Sorocabana-APTA, in Presidente Prudente, SP. The parameters evaluated were fruit mass, length, sutural diameter, yield per plant, soluble solids content and titratable acidity. The evaluations allowed to conclude that the rootstocks affected the mass of fruits, and Umê showed bigger average mass. In 2006, the results showed a significative increment of yield in all cultivars, and Doçura 2 cultivar when compared to Umê showed values above the average. Doçura 2 cultivar when compared to Okinawa root-stock was distinguished by congregating better fruit physical characteristics and yield per plant. Talismã and Dourado 2 cultivars showed fruits with bigger mass, length and sutural diameter of fruits.Tropical cultivar was distinguished by better quality characteristics, without depending on the root-stock.

Index terms: Prunus persica L, quality, production, ratio.

\section{INTRODUÇÃO}

São Paulo participa com aproximadamente $22 \%$ da produção nacional de pêssegos (IBGE, 2006), destacando-se o município de. Paranapanema como o maior produtor estadual, com 6,3 mil toneladas na safra de 2004-2005 (IEA, 2005). A totalidade da produção paulista de pêssego destina-se ao consumo in natura (Sato, 2001) e basicamente as variedades cultivadas estão enxertadas sobre a cultivar Okinawa.

Planta de clima temperado, o pessegueiro (Prunus persica L. Batsch.) exige ocorrência de temperaturas iguais ou inferiores a $7,2^{\circ} \mathrm{C}$ para sair do estado de dormência (Pereira et al., 2002). $\mathrm{O}$ Instituto Agronômico de Campinas-IAC, lançou várias cultivares com baixa exigência de frio, com necessidade inferior a 100 horas, adaptadas às regiões de clima mais ameno, tipicamente subtropical, o que permitiu o desenvolvimento da persicultura em outras regiões. Estudos de comportamento têm mostrado que as condições climáticas podem interferir nos processos fisiológicos da planta, determinando maior ou menor adaptação à região de cultivo (Nienow, 1997).

No melhoramento genético do pessegueiro, pouca importância foi dada ao porta-enxerto (Raseira \& Nakasu, 2002), que influencia diversas características da copa de frutas de caroço, como área de seção do tronco, altura da planta, formato e crescimento da copa, comprimento e ângulo de abertura dos ramos, florescimento, produção de frutos, época de senescência das folhas e sobrevivência da planta (Guerriero et al., 1989).

Pesquisas desenvolvidas no IAC com o Umezeiro (Prunus x mume Sieb \& Zucc.) mostraram a viabilidade técnica da enxertia entre as duas espécies, com antecipação do florescimento, redução do vigor e da massa dos frutos, aumento no teor de sólidos solúveis (Mayer et al., 2006) e da coloração vermelha, em relação aos frutos produzidos pelas mesmas cultivares enxertadas em ‘Okinawa' (Campo-Dall'Orto et al., 1992; Campo-Dall'Orto et al., 1994).

O pêssego é um fruto climatérico em que as

1(Trabalho 048-08). Recebido em: 19-09-2008. Aceito para publicação 28-02-2008. Parte da tese do primeiro autor, apresentado à FEIS/UNESP, para obtenção do título de Doutor.Trabalho desenvolvido com Auxílio à pesquisa da FAPESP (Processo $\mathrm{n}^{\circ}$ 05/55649-5).

${ }^{2} \mathrm{Eng}^{\circ} \mathrm{Agr}^{\circ} \mathrm{PqCMsc}$.APTA-Pólo Regional Alta Sorocabana Caixa 298 Cep 19015-970 Presidente Prudente-SP soniamontes@apta.sp.gov.br ${ }^{3} \mathrm{Eng}^{\mathrm{O}} \mathrm{Agr}{ }^{\circ}$ Prof.Dr.FEIS/UNESP Caixa 56 Cep 15385-000 Ilha Solteira-SP boliani@agr.feis.unesp.br , santospc@agr.feis.unesp.br

${ }^{4} \mathrm{Eng}^{\circ}{ }^{\mathrm{Agr}}{ }^{\circ} \mathrm{PqC}$.Dr. Instituto Biológico- CEE Caixa 70 Cep 13000-000 Campinas-SP adalton@ biologico.sp.gov.br 
transformações resultantes do amadurecimento tem continuidade após ser retirado da planta-mãe, evidenciando a importância de se saber qual o momento apropriado de colheita das frutas (Sachs \& Campos, 1998). No presente trabalho, objetivou-se avaliar as características produtivas, físicas e químicas dos frutos de seis cultivares de pessegueiros: Talismã, Tropical, Aurora 1, Dourado 2, Doçura 2 e Aurora 2, sobre os porta-enxertos 'Okinawa' e Umê, cultivadas na região oeste do Estado de São Paulo.

\section{MATERIAL E MÉTODOS}

O ensaio foi implantado em solo tipo Argissolo Vermelho, textura arenosa, em local com altitude de $424 \mathrm{~m}$, latitude $22^{\circ} 11^{\prime} \mathrm{S}$ e longitude $51^{\circ} 23^{\prime} \mathrm{W}$. O clima, segundo a classificação de Köpen é Aw, tropical chuvoso com inverno seco. A temperatura média anual é de $23^{\circ} \mathrm{C}$ e a precipitação anual de $1.287,7 \mathrm{~mm}$ (CEPAGRI, 2007).

O pomar foi instalado em dezembro de 2001, no Pólo Regional Alta Sorocabana-APTA, município de Presidente Prudente-SP. As mudas foram produzidas no Centro de Fruticultura-APTA, em Jundiaí, instaladas num espaçamento de $6,0 \times 3,0 \mathrm{~m}$ para o porta-enxerto Okinawa, $6,0 \times 1,5 \mathrm{~m}$ para o Umê e conduzidas no sistema de vaso com 4 pernadas para 'Okinawa' e 2 pernadas para Umê.

Os tratos culturais durante a condução do estudo foram os convencionais indicados para a cultura (Pereira et al., 2002), como: superação da dormência artificial realizada com Cianamida hidrogenada $(0,5 \%)$ + óleo mineral $(1 \%)$, raleio de frutos, adubações, controle de plantas espontâneas, podas, tratamentos fitossanitários e irrigação por microaspersão. O raleio foi realizado deixando-se 2 frutos/ramo, quando a distância maior que $10 \mathrm{~cm}$, voltados para baixo preferencialmente. Foram avaliadas seis cultivares (Talismã, Tropical, Aurora 1, Dourado 2, Doçura 2 e Aurora 2) e dois porta-enxertos, num delineamento em blocos ao acaso, com cinco repetições e uma planta por parcela.

As avaliações foram realizadas em três anos consecutivos (2004, 2005, 2006) para as características físicas e produtivas, e dois anos para SS e AT (2005 e 2006).

A massa, o comprimento e o diâmetro sutural do fruto e as determinações de Sólidos solúveis e Acidez titulável foram obtidos a partir de uma amostra de cinco frutos por planta, em cinco plantas, totalizando 25 frutos fisiologicamente bem desenvolvidos. As características físicas foram determinadas no período de agosto a novembro de 2004, julho a setembro de 2005 e agosto a novembro de 2006, e as químicas no período de agosto a setembro em 2005 e setembro a outubro em 2006. Definiu-se como estádio de frutos maduros quando a extremidade inferior cedia à pressão do polegar.

A polpa dos frutos foi obtida após serem descascados e homogeneizados em liquidificador doméstico, e coagem em peneira plástica. O teor de SS foi determinado por refratometria, e os resultados corrigidos pela temperatura, expressos em ${ }^{\circ}$ Brix. A AT foi obtida por titulação de 20 gramas de suco das frutas acrescidas de $20 \mathrm{~mL}$ de água destilada, com solução de hidróxido de sódio a $0,1 \mathrm{~N}$, com resultados expressos em $\mathrm{g}$ de ácido cítrico/ $100 \mathrm{~g}$ de polpa (INSTITUTO ADOLFO LUTZ, 1985). O ratio foi calculado por meio da relação SS/AT. Os dados foram analisados individualmente em cada safra e para cada porta-enxerto, pelo Teste de Scott-Knott.

\section{RESULTADOS E DISCUSSÃO}

Nos três anos avaliados, houve comportamento diferenciado entre as cultivares com relação às características físicas dos frutos (massa, comprimento e diâmetro sutural) (Tabela 2). As cvs. Talismã e Dourado 2 apresentaram comportamento estatisticamente igual sobre 'Okinawa', com os maiores valores médios de massa e diâmetro sutural por fruto, na média dos 3 anos, diferindo estatisticamente das demais. A cv. Talismã foi o que apresentou os frutos de maior comprimento. No sul de Minas Gerais, a cv. Talismã sobressaiu-se quando comparada à Alô-Doçura, Cristal, Rei da conserva, Campinas I e Brasão, com frutos maiores, mais compactos e com maior relação polpa/caroço, com valores de 4,29 cm de comprimento e diâmetro sutural de 4,44 cm (Teixeira et al.,1983). Entretanto, os valores obtidos pelos autores foram inferiores aos obtidos neste estudo. Chitarra et al. (1981), para a cv. Talismã, obtiveram frutos com diâmetro transversal de $4,74 \mathrm{~cm}$, menor que a média dos três anos neste trabalho.

As cvs. Talismã e Dourado 2 sobre 'Umê' apresentaram maiores valores de massa e comprimento dos frutos, na média dos três anos, diferindo estatisticamente dos demais (Tabela 3). O diâmetro dos frutos não diferiu entre as cultivares na média dos três anos. Apenas no ano de 2005, as cvs. Talismã, Aurora 1 e Aurora 2 apresentaram os maiores valores de diâmetro sutural dos frutos, que diferiram dos demais. Os resultados obtidos concordam com Barbosa et al. (1998), que observaram o bom desenvolvimento de frutos de Talismã em plantios adensados com massa de 89,8 g, 97,7 g e 99,3 g nos os espaçamentos de 4,0 x 0,5 m; 4,0 x 1,0 m e 4,0 x 1,5 $\mathrm{m}$, respectivamente.

Os valores de diâmetro dos frutos obtidos no trabalho permitem enquadrar os pêssegos como tipo 3 (49 a $56 \mathrm{~mm}$ ), para a indústria, para a região Sudeste (Medeiros \& Raseira, 1998) e calibre 3 (diâmetro de 51 a $56 \mathrm{~mm}$ ), segundo o Programa Paulista para a Melhoria dos Padrões Comerciais e Embalagens de Hortifrutigranjeiros. No CEAGESP de São Paulo, predominam pêssegos de calibres 2; 3; 4 e 5 no processo de comercialização pelos atacadistas (Almeida, 2006), portanto, embora não tendo apresentado altas produções, os frutos obtidos estão dentro dos padrões praticados.

Analisando conjuntamente as características físicas dos frutos nos três anos avaliados, observa-se que frutos maiores foram obtidos nos anos de 2004 e 2006. Desta forma, as diferenças entre as cultivares podem ser explicadas pelo efeito genético, e não pelo efeito dos anos. A menor produção observada em 2005, possivelmente, possa ser explicada pela ocorrência de dois surtos de florescimento (abril a agosto/2005), sendo que, no segundo, não houve fixação de frutos. A alta precipitação pluvial ocorrida em janeiro/2005 causou incidência de ferrugem que acarretou desfolha precoce das plantas e antecipação do florescimento (Tabela 1).

As cvs. Talismã, Aurora 1 e Doçura 2 apresentaram maior produção por planta em 2005 para o porta-enxerto Okinawa, diferindo das demais. A cv. Talismã, apesar de apresentar menor número de 
frutos, compensou a produção devido ao elevado peso individual dos frutos. No ano de 2006, embora o coeficiente de variação elevado não tenha permitido apontar a diferença entre as cultivares, o maior valor na produção foi observada nas cvs. Talismã e Doçura 2 (Tabela 4).

Utilizando o porta-enxerto Umê (Tabela 5), a maior produção foi na Aurora 1, em 2005, diferindo das demais, devido, provavelmente, ao maior número de frutos/planta. Em 2006, embora não tenha sido observada diferença significativa entre as cultivares, apresentaram tendência de maior valor de produção/área e por planta as cvs. Talismã e Doçura 2, com maior número de frutos/planta e maior massa. Os dados observados para a cv. Doçura 2 são maiores que os constatados por Ogata (1973), que obteve 27 frutos por planta, com massa média de $63 \mathrm{~g}$ e produção de $1.713,0 \mathrm{~g}$ por planta, em plantio adensado, na região de Anápolis (GO). De maneira generalizada, para os dois porta-enxertos analisados, a baixa produtividade está relacionada ao reduzido número de frutos por planta, em decorrência do elevado índice de aborto ocorrido.

As cvs. Talismã e Tropical sobre o porta-enxerto Okinawa foram as que produziram frutos com maiores teores de SS em 2005 (14,55 e 13,14 ${ }^{\circ}$ Brix), e o cv. Tropical em 2006 (13,82 ${ }^{\circ}$ Brix $)$ (Tabela 6). Os resultados obtidos para a cv. Tropical foram superiores aos obtidos por Nienow (1997) na região de Jaboticabal, que foi de $12,83^{\circ}$ Brix, mas inferiores aos $16^{\circ} \mathrm{Brix}$ obtidos por Barbosa et al. (1989) em Monte Alegre do Sul (SP). Em relação à AT, as cvs. Talismã, Aurora 1, Dourado 2, Doçura 2 e Aurora 2, sobre o portaenxerto Okinawa, apresentaram os frutos mais ácidos, diferindo da cv. Tropical, com frutos menos ácidos, em 2006. Em 2005, as cultivares não diferiram entre si. A cv. Tropical apresentou a melhor relação SS/AT, usualmente utilizada para avaliar o grau de maturação dos frutos e indicativa do gosto, com frutos de maior valor de ratio na média dos dois anos avaliados, diferindo das demais.

No porta-enxerto Umê, as cultivares não diferiram nos valores de SS, entretanto, nos frutos da cv. Doçura 2, houve maiores teores em 2005 e das cvs. Tropical e Doçura 2 em 2006 (Tabela 7). Frutos menos ácidos foram produzidos pelas cvs. Tropical, Aurora 1 e Aurora 2 em 2005 e Tropical em 2006, que diferiram das demais. Resultados superiores foram obtidos por Mathias et al. (2008) para a cv. Aurora 1 sobre o porta-enxerto Okinawa, com SS variando de 12,10 a $12,95^{\circ}$ Brix e AT de 0,38 a 0,40. A cv. Tropical apresentou a melhor relação SS/AT, com frutos de maior ratio em 2005 e 2006, para os dois porta-enxertos.

TABELA 1 - Precipitação e temperatura médias do período experimental. Presidente Prudente-SP.

\begin{tabular}{|c|c|c|c|c|c|c|}
\hline \multirow{2}{*}{ Mês } & \multicolumn{3}{|c|}{ Precipitação $(\mathrm{mm})$ * } & \multicolumn{3}{|c|}{ Temperatura (média) $\left({ }^{\circ} \mathrm{C}\right) *$} \\
\hline & 2004 & 2005 & 2006 & 2004 & 2005 & 2006 \\
\hline Janeiro & 133,9 & 328,2 & 174,4 & 26,0 & 24,5 & 26,4 \\
\hline Fevereiro & 80,8 & 20,2 & 281,3 & 25,8 & 25,5 & 25,8 \\
\hline Março & 175,7 & 55,5 & 159,1 & 25,6 & 26,7 & 26,1 \\
\hline Abril & 35,2 & 71,1 & 9,5 & 24,8 & 25,9 & 24,1 \\
\hline Maio & 176,7 & 67,8 & 24,9 & 18,7 & 23,0 & 19,8 \\
\hline Junho & 54,3 & 63,4 & 18,4 & 19,6 & 25,1 & 20,9 \\
\hline Julho & 65,8 & 23,3 & 30,7 & 19,2 & 19,6 & 22,1 \\
\hline Agosto & 0,0 & 72,5 & 14,5 & 22,1 & 23,0 & 23,6 \\
\hline Setembro & 17,5 & 121,2 & 80,0 & 26,5 & 21,1 & 22,5 \\
\hline Outubro & 248,4 & 155,2 & 102,7 & 23,3 & 24,9 & 25,7 \\
\hline Novembro & 140,1 & 45,4 & 65,5 & 25,0 & 24,8 & 26,5 \\
\hline Dezembro & 101,6 & 64,9 & 352,4 & 25,6 & 25,6 & 26,5 \\
\hline
\end{tabular}

* Dados fornecidos pela Estação Meteorológica da FCT/UNESP de Presidente Prudente.

TABELA 2 - Massa, comprimento e diâmetro sutural de frutos das cultivares de pessegueiros enxertadas sobre 'Okinawa'. Presidente Prudente- SP. 2004/2006.

\begin{tabular}{|c|c|c|c|c|c|c|c|c|c|c|c|c|}
\hline \multirow{3}{*}{ Cultivares } & \multicolumn{11}{|c|}{ Porta-enxerto Okinawa } & \multirow[b]{3}{*}{ Média } \\
\hline & \multicolumn{3}{|c|}{ Massa/fruto $(\mathrm{g})$} & \multicolumn{5}{|c|}{ Comprimento $(\mathrm{cm})$} & \multicolumn{3}{|c|}{ Diâmetro sutural $(\mathrm{cm})$} & \\
\hline & 2004 & 2005 & 2006 & Média & 2004 & 2005 & 2006 & Média & 2004 & 2005 & 2006 & \\
\hline Talismã & 95,48 a & $61,40 \mathrm{a}$ & $79,99 \mathrm{~b}$ & $79,04 \mathrm{a}$ & $6,07 \mathrm{a}$ & $5,32 \mathrm{a}$ & $6,06 \mathrm{a}$ & $5,82 \mathrm{a}$ & $5,61 \mathrm{a}$ & $4,79 \mathrm{a}$ & $5,17 \mathrm{~b}$ & $5,19 \mathrm{a}$ \\
\hline Tropical & $66,64 \mathrm{~b}$ & $48,79 \mathrm{~b}$ & $81,29 \mathrm{~b}$ & $66,00 \mathrm{~b}$ & $5,10 \mathrm{c}$ & $4,66 \mathrm{~b}$ & $5,48 \mathrm{~b}$ & $5,08 \quad \mathrm{~d}$ & $5,01 \mathrm{~b}$ & $4,35 \mathrm{~b}$ & $5,31 \mathrm{~b}$ & $4,89 \mathrm{~b}$ \\
\hline Aurora-1 & $61,35 \mathrm{~b}$ & $41,13 \mathrm{~b}$ & $69,02 \mathrm{~b}$ & $56,91 \mathrm{c}$ & $5,17 \mathrm{c}$ & $4,53 \mathrm{~b}$ & $5,65 \mathrm{~b}$ & $5,12 \mathrm{~d}$ & $4,79 \mathrm{~b}$ & $4,08 \mathrm{~b}$ & $4,87 \mathrm{c}$ & $4,58 \mathrm{c}$ \\
\hline Dourado-2 & 87,31 a & $48,05 \mathrm{~b}$ & 98,29 a & 78,16 a & $5,90 \mathrm{a}$ & $4,93 \mathrm{~b}$ & $6,08 \mathrm{a}$ & $5,64 \mathrm{~b}$ & $5,34 \mathrm{a}$ & $4,27 \mathrm{~b}$ & $5,78 \mathrm{a}$ & $5,13 \mathrm{a}$ \\
\hline Doçura-2 & 80,11 a & $44,19 \mathrm{~b}$ & $75,63 \mathrm{~b}$ & $68,02 \mathrm{~b}$ & $5,64 \mathrm{~b}$ & $4,72 \mathrm{~b}$ & $5,65 \mathrm{~b}$ & $5,33 \mathrm{c}$ & $5,38 \mathrm{a}$ & $4,29 \mathrm{~b}$ & $5,32 \mathrm{~b}$ & $5,00 \mathrm{~b}$ \\
\hline Aurora-2 & $86,20 \mathrm{a}$ & $45,89 \mathrm{~b}$ & $75,53 \mathrm{~b}$ & $68,62 \mathrm{~b}$ & $5,68 \mathrm{~b}$ & $4,70 \mathrm{~b}$ & $5,73 \mathrm{~b}$ & $5,37 \mathrm{c}$ & $5,47 \mathrm{a}$ & $4,29 \mathrm{~b}$ & $5,31 \mathrm{~b}$ & $5,02 \mathrm{~b}$ \\
\hline Média & $79,52 \mathrm{~A}$ & $48,24 \mathrm{~B}$ & $79,96 \mathrm{~A}$ & $69,12 \mathrm{~A}$ & $5,59 \mathrm{~B}$ & $4,81 \quad \mathrm{C}$ & $5,78 \mathrm{~A}$ & $5,39 \mathrm{~B}$ & $5,27 \mathrm{~A}$ & $4,36 \mathrm{~B}$ & $5,29 \mathrm{~A}$ & $4,97 \mathrm{~A}$ \\
\hline F var. & $3,51 *$ & $6,35 *$ & $3,92 *$ & . & $6,38 *$ & $7,86 *$ & $3,48 *$ & . & $3,21 *$ & $5,37 *$ & $4,56^{*}$ & . \\
\hline C.V.\% & 35,22 & 32,86 & 29,01 & & 12,14 & 11,61 & 11,34 & & 12,51 & 13,45 & 12,22 & \\
\hline
\end{tabular}

* Médias seguidas de mesma letra maiúscula na linha e minúscula na coluna não diferem entre si, pelo Teste de Scott-Knott, a 5\% de probabilidade de erro. 
TABELA 3 - Massa, comprimento e diâmetro sutural de frutos das cultivares de pessegueiros enxertadas sobre Umê. Presidente Prudente-SP.

\begin{tabular}{|c|c|c|c|c|c|c|c|c|c|c|c|c|}
\hline \multirow{3}{*}{ Cultivares } & \multicolumn{11}{|c|}{ Porta-enxerto Umê } & \multirow[b]{3}{*}{ Média } \\
\hline & \multicolumn{3}{|c|}{ Massa/fruto $(\mathrm{g})$} & \multicolumn{4}{|c|}{ Comprimento $(\mathrm{cm})$} & \multicolumn{4}{|c|}{ Diâmetro sutural $(\mathrm{cm})$} & \\
\hline & 2004 & 2005 & 2006 & Média & 2004 & 2005 & 2006 & Média & 2004 & 2005 & 2006 & \\
\hline Talismã & $103,81 \mathrm{a}$ & 70,99 a & $87,92 \mathrm{a}$ & $87,57 \mathrm{a}$ & $6,57 \mathrm{a}$ & $5,60 \mathrm{a}$ & 6,13 & $6,08 \mathrm{a}$ & 5,70 & $4,93 \mathrm{a}$ & $5,26 \mathrm{a}$ & $5,30 \mathrm{a}$ \\
\hline Tropical & 88,91 a & $40,31 \mathrm{~b}$ & $91,01 \mathrm{a}$ & $73,41 \mathrm{~b}$ & $5,64 \mathrm{~b}$ & $4,43 \mathrm{~b}$ & 5,48 & $5,18 \mathrm{~b}$ & 5,36 & $4,03 \mathrm{~b}$ & $5,43 \mathrm{a}$ & $4,94 \mathrm{a}$ \\
\hline Aurora-1 & $72,10 \mathrm{~b}$ & 58,82 a & $78,00 \mathrm{a}$ & $69,64 \mathrm{~b}$ & $5,56 \mathrm{~b}$ & $5,02 \mathrm{~b}$ & 5,88 & $5,49 \mathrm{~b}$ & 5,24 & $4,66 \mathrm{a}$ & $5,14 \mathrm{a}$ & $5,01 \mathrm{a}$ \\
\hline Dourado-2 & $99,52 \mathrm{a}$ & $47,03 \mathrm{~b}$ & $101,92 \mathrm{a}$ & 80,49 a & $6,37 \mathrm{a}$ & $5,25 \mathrm{a}$ & 6,06 & $5,89 \mathrm{a}$ & 5,89 & $4,29 \mathrm{~b}$ & $5,76 \mathrm{a}$ & $5,31 \mathrm{a}$ \\
\hline Doçura-2 & $77,51 \mathrm{~b}$ & $53,76 \mathrm{~b}$ & $89,30 \mathrm{a}$ & $73,52 \mathrm{~b}$ & $5,24 \mathrm{~b}$ & $4,75 \mathrm{~b}$ & 5,70 & $5,23 \mathrm{~b}$ & 5,39 & $4,38 \mathrm{~b}$ & $5,55 \mathrm{a}$ & $5,11 \mathrm{a}$ \\
\hline Aurora-2 & $58,26 \mathrm{c}$ & $50,80 \mathrm{~b}$ & $78,92 \mathrm{a}$ & $62,66 \mathrm{~b}$ & $5,19 \mathrm{~b}$ & $4,98 \mathrm{~b}$ & 5,73 & $5,30 \mathrm{~b}$ & 4,95 & $4,52 \mathrm{a}$ & $5,14 \mathrm{a}$ & $4,87 \mathrm{a}$ \\
\hline Média & $82,19 \mathrm{~A}$ & $53,62 \mathrm{~B}$ & $87,85 \mathrm{~A}$ & $74,55 \mathrm{~A}$ & $5,76 \mathrm{~A}$ & $5,00 \mathrm{~B}$ & $5,83 \mathrm{~A}$ & 5,53 A & $5,42 \mathrm{~A}$ & 4,47 B & $5,38 \mathrm{~A}$ & $5,09 \mathrm{~A}$ \\
\hline F var. & $4,61 *$ & 3,69 * & $2,32 *$ & & $5,23 *$ & 3,39 * & $1,48 \mathrm{n} . \mathrm{s}$ & & $1,58 \mathrm{n} . \mathrm{s}$ & $2,80^{*}$ & $2,43 *$ & \\
\hline C.V.\% & 31,99 & 43,15 & 30,94 & & 16,41 & 18,67 & 15,64 & & 15,32 & 18,17 & 14,05 & \\
\hline
\end{tabular}

* Médias seguidas de mesma letra maiúscula na linha e minúscula na coluna não diferem entre si, pelo Teste de Scott-Knott, a 5\% de probabilidade de erro.

TABELA 4 - Número, massa média de frutos e produção por planta e por hectare de cultivares de pessegueiros enxertadas sobre 'Okinawa'. Presidente Prudente-SP. 2005/2006.

\begin{tabular}{|c|c|c|c|c|c|c|c|c|}
\hline \multirow{3}{*}{ Cultivares } & \multicolumn{8}{|c|}{ Porta -enxerto Okinawa } \\
\hline & \multicolumn{4}{|c|}{2005} & \multicolumn{4}{|c|}{2006} \\
\hline & $\begin{array}{l}\mathrm{N}^{\circ} \text { frutos / } \\
\text { planta }\end{array}$ & $\begin{array}{l}\text { Massa } \\
\text { média / } \\
\text { fruto }(\mathrm{g})\end{array}$ & $\begin{array}{l}\text { Produção/ } \\
\text { Planta } \\
\text { (kg) }\end{array}$ & $\begin{array}{l}\text { Produção / } \\
\text { ha (kg) }\end{array}$ & $\begin{array}{l}\mathrm{N}^{\circ} \text { frutos } / \\
\text { Planta }\end{array}$ & $\begin{array}{l}\text { Massa } \\
\text { média / } \\
\text { fruto }(\mathrm{g})\end{array}$ & $\begin{array}{l}\text { Produção/ } \\
\text { Planta } \\
(\mathrm{kg})\end{array}$ & $\begin{array}{c}\text { Pro dução/ } \\
\text { ha } \\
(\mathrm{kg})\end{array}$ \\
\hline Talismã & $21,43 \mathrm{~b}$ & 61,83 & $1,33 \mathrm{a}$ & $737,97 \mathrm{a}$ & $47,86 \mathrm{a}$ & $78,26 \mathrm{~b}$ & 3,86 & $2.148,50$ \\
\hline Tropical & $7,29 \mathrm{~b}$ & 43,87 & $0,29 \mathrm{~b}$ & $160,45 \mathrm{~b}$ & $38,24 \mathrm{~b}$ & $80,40 \mathrm{~b}$ & 3,37 & $1.872,90$ \\
\hline Aurora-1 & $40,17 \mathrm{a}$ & 39,73 & $1,76 \mathrm{a}$ & $980,98 \mathrm{a}$ & $39,56 \mathrm{~b}$ & $70,44 \mathrm{~b}$ & 2,55 & $1.416,30$ \\
\hline Dourado-2 & $14,80 \mathrm{~b}$ & 40,27 & $0,69 \mathrm{~b}$ & $380,78 \mathrm{~b}$ & $27,85 \mathrm{~b}$ & 99,44 a & 3,42 & $2.011,20$ \\
\hline Doçura-2 & $28,14 \mathrm{a}$ & 45,97 & $1,30 \mathrm{a}$ & $723,75 \mathrm{a}$ & $72,06 \mathrm{a}$ & $72,66 \mathrm{~b}$ & 5,74 & $3.189,90$ \\
\hline Aurora-2 & $7,67 \mathrm{~b}$ & 44,77 & $0,39 \mathrm{~b}$ & $218,57 \mathrm{~b}$ & $22,43 \mathrm{~b}$ & $74,29 \mathrm{~b}$ & 1,74 & 966.50 \\
\hline Média & 19,97 & 46,58 & 0,955 & 531,19 & 43,55 & 79,68 & 3,49 & $1.958,01$ \\
\hline F var. & $4,01 *$ & $2,54 \mathrm{~ns}$ & $2,94 *$ & 2,94 * & 3,18 * & 3,40 * & $1,81 \mathrm{~ns}$ & $1,64 \mathrm{~ns}$ \\
\hline C.V $\%$ & 81,05 & 26,23 & 90,88 & 90,88 & 55,39 & 15,56 & 64,71 & 64,71 \\
\hline
\end{tabular}

* Médias seguidas de mesma letra não diferem entre si, pelo Teste de Scott-Knott, a 5\% de probabilidade de erro.

TABELA 5 - Número, massa média de frutos e produção por planta de cultivares de pessegueiros enxertadas sobre Umê. Presidente Prudente-SP. 2005/2006.

\begin{tabular}{|c|c|c|c|c|c|c|c|c|}
\hline \multirow{3}{*}{ Cultivares } & \multicolumn{8}{|c|}{ Porta -enxerto Umê } \\
\hline & \multicolumn{4}{|l|}{2005} & \multicolumn{4}{|l|}{2006} \\
\hline & $\begin{array}{l}\mathrm{N}^{\circ} \text { frutos / } \\
\text { Planta }\end{array}$ & $\begin{array}{l}\text { Massa } \\
\text { média / } \\
\text { fruto }(\mathrm{g})\end{array}$ & $\begin{array}{l}\text { Produção/ } \\
\text { Planta } \\
\text { (kg) }\end{array}$ & $\begin{array}{l}\text { Produção/ } \\
\text { ha } \\
\mathrm{kg}\end{array}$ & $\begin{array}{l}\mathrm{N}^{\circ} \text { frutos / } \\
\text { Planta }\end{array}$ & $\begin{array}{l}\text { Massa } \\
\text { Média / } \\
\text { fruto }(\mathrm{g})\end{array}$ & $\begin{array}{l}\text { Produção/ } \\
\text { Planta } \\
\text { (kg) }\end{array}$ & $\begin{array}{l}\text { Produção/ } \\
\text { ha } \\
(\mathrm{kg})\end{array}$ \\
\hline Talismã & $8,14 \mathrm{~b}$ & 61,94 & $0,52 \mathrm{~b}$ & 576,50 & 34,00 & 90,98 & 3,23 & $3.590,00$ \\
\hline Tropical & $7,00 \mathrm{~b}$ & 39,98 & $0,26 \mathrm{~b}$ & 288,86 & 27,57 & 84,99 & 1,88 & $2.092,00$ \\
\hline Aurora-1 & $25,57 \mathrm{a}$ & 54,99 & $1,56 \mathrm{a}$ & $1.733,16$ & 27,50 & 71,59 & 1,70 & $1.887,00$ \\
\hline Dourado-2 & $4,08 \mathrm{~b}$ & 53,05 & $0,21 \mathrm{~b}$ & 184,40 & 17,20 & 103,63 & 1,87 & $2.079,00$ \\
\hline Doçura-2 & $12,14 \mathrm{~b}$ & 56,27 & $0,70 \mathrm{~b}$ & 777,70 & 35,83 & 88,32 & 3,19 & $3.548,00$ \\
\hline Aurora-2 & $5,14 \mathrm{~b}$ & 47,46 & $0,24 \mathrm{~b}$ & 266,64 & 7,67 & 69,54 & 0,59 & 658,00 \\
\hline Média & 10,41 & 52,27 & 0,58 & 890,02 & 25,00 & 84,13 & 2,05 & $2.272,69$ \\
\hline F var. & $5,07^{*}$ & $1,43 \mathrm{~ns}$ & $3,12 *$ & $1,25 \mathrm{~ns}$ & $1,60 \mathrm{~ns}$ & $2,16 \mathrm{~ns}$ & $1,72 \mathrm{~ns}$ & $1,72 \mathrm{~ns}$ \\
\hline C.V \% & 88,95 & 32,31 & 130,90 & 178,41 & 80,47 & 24,18 & 88,77 & 88,76 \\
\hline
\end{tabular}

* Médias seguidas de mesma letra não diferem entre si, pelo Teste deScott-Knott, a $5 \%$ de probabilidade de erro.

TABELA 6- Sólidos solúveis (SS), acidez titulável (AT) e ratio (SS/AT) de cultivares de pessegueiros enxertadas sobre 'Okinawa'. Presidente Prudente-SP. 2005/2006.

\begin{tabular}{lccccccc}
\hline \multicolumn{7}{c}{ SS ( ${ }^{\circ}$ Brix) } & \multicolumn{7}{c}{ AT (\% ác.citrico) } & \multicolumn{3}{c}{ ratio (SS/AT) } \\
\cline { 2 - 9 } \multicolumn{1}{c}{ Cultivares } & 2005 & 2006 & 2005 & 2006 & 2005 & 2006 & Média \\
\hline Talismã & $14,55 \mathrm{a}$ & $10,74 \mathrm{~b}$ & 0,2288 & $0,3654 \mathrm{a}$ & 67,76 & $29,76 \mathrm{~b}$ & $48,76 \mathrm{~b}$ \\
Tropical & $13,14 \mathrm{a}$ & $13,82 \mathrm{a}$ & 0,1891 & $0,1165 \mathrm{~b}$ & 73,91 & $111,16 \mathrm{a}$ & $92,59 \mathrm{a}$ \\
Aurora-1 & $10,75 \mathrm{~b}$ & $10,34 \mathrm{~b}$ & 0,1556 & $0,2800 \mathrm{a}$ & 69,64 & $41,50 \mathrm{~b}$ & $55,57 \mathrm{~b}$ \\
Dourado-2 & $11,03 \mathrm{~b}$ & $9,32 \mathrm{~b}$ & 0,2021 & $0,4169 \mathrm{a}$ & 60,82 & $23,23 \mathrm{~b}$ & $42,03 \mathrm{c}$ \\
Doçura-2 & $12,04 \mathrm{~b}$ & $11,18 \mathrm{~b}$ & 0,3226 & $0,4423 \mathrm{a}$ & 42,00 & $28,47 \mathrm{~b}$ & $35,27 \mathrm{c}$ \\
Aurora-2 & $9,35 \mathrm{~b}$ & $10,63 \mathrm{~b}$ & 0,1676 & $0,2968 \mathrm{a}$ & 53,00 & $36,73 \mathrm{~b}$ & $45,10 \mathrm{c}$ \\
\hline Média & 11,99 & 10,71 & 0,2204 & 0,3450 & $61,29 \mathrm{~A}$ & $38,29 \mathrm{~B}$ & 53,22 \\
F var. & $3,31 *$ & $3,69 *$ & $1,99 \mathrm{~ns}$ & $3,55 *$ & $2,13 \mathrm{~ns}$ & $24,28 *$ &. \\
C.V.\% & 19,19 & 13,82 & 37,41 & 35,50 & 30,75 & 30,71 & 31,44 \\
\hline
\end{tabular}

* Médias seguidas de mesma letra não diferem entre si, pelo Teste de Scott-Knott, a 5\% de probabilidade de erro. 
TABELA 7 - Sólidos solúveis (SS), acidez titulável (AT) e ratio (SS/AT) de cultivares de pessegueiros enxertadas sobre Umê. Presidente Prudente-SP. 2005/2006.

\begin{tabular}{|c|c|c|c|c|c|c|c|}
\hline \multirow[b]{3}{*}{ Cultivares } & \multicolumn{7}{|c|}{ Porta -enxerto Umê } \\
\hline & \multicolumn{2}{|c|}{ SS ( ${ }^{\circ}$ Brix) } & \multicolumn{2}{|c|}{ AT (\% ác.citrico) } & \multicolumn{2}{|c|}{ ratio $(\mathrm{SS} / \mathrm{AT})$} & \multirow[t]{2}{*}{ Média } \\
\hline & 2005 & 2006 & 2005 & 2006 & 2005 & 2006 & \\
\hline Talismã & 12,69 & 10,16 & 0,2817 a & $0,3715 \mathrm{a}$ & $46,74 \mathrm{~b}$ & $26,99 \mathrm{~b}$ & $37,21 \mathrm{~b}$ \\
\hline Tropical & 10,91 & 11,94 & $0,0953 \mathrm{~b}$ & $0,1777 \mathrm{~b}$ & 98,47 a & $72,22 \mathrm{a}$ & 83,66 a \\
\hline Aurora-1 & 10,32 & 11,01 & $0,1988 \mathrm{~b}$ & $0,3026 \mathrm{a}$ & $57,56 \mathrm{~b}$ & $39,00 \mathrm{~b}$ & $48,28 \mathrm{~b}$ \\
\hline Dourado-2 & 12,32 & 10,53 & $0,3173 \mathrm{a}$ & $0,3175 \mathrm{a}$ & $33,88 \mathrm{~b}$ & $34,38 \mathrm{~b}$ & $36,35 \mathrm{~b}$ \\
\hline Doçura-2 & 13,63 & 11,87 & $0,2383 \mathrm{a}$ & $0,3186 \mathrm{a}$ & $60,58 \mathrm{~b}$ & $38,33 \mathrm{~b}$ & $49,46 \mathrm{~b}$ \\
\hline Aurora-2 & 8,65 & 9,89 & $0,1494 \mathrm{~b}$ & $0,3336 \mathrm{a}$ & $60,93 \mathrm{~b}$ & $31,78 \mathrm{~b}$ & $44,35 \mathrm{~b}$ \\
\hline Média & 11,28 & 10,95 & 0,206 & 0,2981 & $62,39 \mathrm{~A}$ & $41,34 \mathrm{~B}$ & 49,89 \\
\hline F var. & $2,18 \mathrm{~ns}$ & $1,12 \mathrm{~ns}$ & $5,09 *$ & $4,39 *$ & $3,48 *$ & $8,84 *$ & . \\
\hline C.V.\% & 25,51 & 19,03 & 32,05 & 24,24 & 34,62 & 30,95 & 33,09 \\
\hline
\end{tabular}

* Médias seguidas de mesma letra não diferem entre si, pelo Teste de Scott-Knott, a 5\% de probabilidade de erro.

\section{CONCLUSÕES}

Nas condições em que foi desenvolvido o presente trabalho, pode-se concluir que:

As cvs. Talismã e Dourado 2 produzem frutos com maiores valores de massa, comprimento e diâmetro sutural, as cultivares com maiores produções por área são Talismã e Doçura 2 e a cv. Tropical a de frutos de maior ratio sobre a 'Okinawa' e Umê.

\section{REFERÊNCIAS}

ALMEIDA, G.V.B. de. Características qualitativas de pêssegos produzidos em Paranapanema-SP, safra 2005, e sua valoração no mercado atacadista de São Paulo. 2006. 66 f. Dissertação (Mestrado em Agronomia-Produção Vegetal) - Faculdade de Ciências Agrárias e Veterinárias, Universidade Estadual Paulista, Jaboticabal, 2006

BARBOSA, W.; CAMPO-DALL'ORTO, F.A.; OJIMA, M. O pessegueiro no sistema de pomar compacto: conjeturas, experimentação e prática. O Agronômico, Campinas, v.41, n.1, p.27-39, 1989 .

BARBOSA, W.; CAMPO-DALL'ORTO, F.A.; OJIMA, M.; SANTOS, R.R. dos. O pessegueiro no sistema de pomar compacto: VIII- Caracterização de cultivares e seleção para diferentes densidades populacionais. Scientia Agricola, Piracicaba, v.55, n.2, p.191-195, 1998.

CAMPO-DALL'ORTO, F.A.; OJIMA, M.; BARBOSA, W.; MARTINS, F.P. O nanismo do pessegueiro induzido pela enxertia no damasqueiro japonês. Pesquisa Agropecuária Brasileira, Brasília, v.27, n.3, p.517-521, 1992.

CAMPO-DALL'ORTO, F.A.; OJIMA, M.; BARBOSA, W.; MARTINS, F.P.; FOBÉ, F.A. Comportamento de pessegueiros do IAC enxertados no damasqueiro japonês e no pessegueiro Okinawa. In: CONGRESSO BRASILEIRO DE FRUTICULTURA, 13., 1994, Salvador Resumos... Salvador: SBF, v.3, 1994. p.879880.
CEPAGRI - Clima dos Municípios Paulistas. Disponível em: $<$ http://www.cpa.unicamp.br/outras-informações/clima-dosmunicipios-paulistas.html>. Acesso em: 24 set. 2007.

CHITARRA, M.I.F.; CHITARRA, A.B.; CARVALHO, V.D. Atributos de qualidade em pêssegos (Prunus persica (L.) Batsch) e relação entre pectina e cálcio durante a maturação. In: CONGRESSO BRASILEIRO DE FRUTICULTURA, 6., 1981, Recife. Anais... Recife: SBF, 1981. p.1085-1098.

GUERRIERO, R.; LORETI, F.; VENTURA, M.; TABANELLI, D. Prove comparative tranuove selezioni e portainnesti del pesco di diversa origine genetica. Revista di Frutticoltura e Ortofloricoltura, Bologna, n.8/9, p.45-49, 1989.

IBGE - Instituto Brasileiro de Geografia e Estatística. Sistema IBGE de Recuperação Automática - SIDRA. Produção agrícola municipal. Disponível em: <http://www.sidra.ibge.gov.br/bda/ acervo/acervo2.asp?>. Acesso em: 19 dez. 2006.

IEA-INSTITUTO DEECONOMIAAGRÍCOLA. Banco de dados IEA. Disponível em: <http://www.iea.sp.gov.br/out/banco/ menu.php>. Acesso em: 20 nov.2005.

INSTITUTO ADOLPHO LUTZ. Normas analíticas, métodos químicos e físicos para análise de alimentos. 3.ed. São Paulo: Instituto Adolpho Lutz, 1985. v.1, 533p.

MATHIAS, C.; MAYER, N.A.; MATTIUZ, B.; PEREIRA, F.M. Efeito de porta-enxertos e espaçamentos entre plantas na qualidade de pêssegos 'Aurora-1'. Revista Brasileira de Fruticultura, Jaboticabal, v.30, n.1, p.165-170, 2008.

MAYER, N.A.; PEREIRA, F.M.; KOBA, V.Y. Desenvolvimento inicial no campo de pessegueiro 'Aurora-1' enxertado em clones de Umezeiro e Okinawa propagados por estacas herbáceas. Revista Brasileira de Fruticultura, Jaboticabal, v.28, n.2, p.231235, 2006.

MEDEIROS, C.A.B.; RASEIRA, M. do C.B. A cultura do pessegueiro. Brasília: Embrapa- SPI; Pelotas: Embrapa: CPACT, 1998.350p. 
NIENOW, A.A. Comportamento morfológico, fenológico e produtivo de cv. de pessegueiro [Prunus persica $(\mathbf{L}$.) Batsch], submetido à poda de renovação após a colheita, na região de Jaboticabal-SP. 1997. 171 f. Tese (Doutorado em Agronomia) Faculdade de Ciências Agrárias e Veterinária, Universidade Estadual Paulista, Jaboticabal, 1997.

OGATA, T. Comportamento de cultivares de pessegueiro, em plantio adensado, submetido à poda drástica, em Anápolis-GO. In: CONGRESSO BRASILEIRO DE FRUTICULTURA, 9., 1973, Campinas. Anais...Campinas: SBF, 1973. p.663-666.

PEREIRA, F.M.; NACHTIGAL, J.C.; ROBERTO, S.R. Tecnologia para a cultura do pessegueiro em regiões tropicais e subtropicais. Jaboticabal: FUNEP, 2002. 61p.
RASEIRA, M. do C.B.; NAKASU, B.H. Pessegueiro. In: BRUCKNER, C.H. (Ed.). Melhoramento de fruteiras de clima temperado. Viçosa: UFV, 2002. p.89-126.

SATO, G.S. Produção de pêssegos de mesa e para indústria no Brasil. Informações Econômicas, São Paulo, v.31, n.6, p. 61-63, 2001.

TEIXEIRA, M.C.R.; CHITARRA, M.I.F; CHITARRA, E.B. Características dos frutos de algumas cultivares de pessegueiros. I-Parâmetros físicos, físico-químicos e químicos na maturação. Revista Brasileira de Fruticultura, Jaboticabal, v.5, p.71-80, 1983. 